\title{
DNA damage-activated ABL-MyoD signaling contributes to DNA repair in skeletal myoblasts
}

\author{
M Simonatto ${ }^{1,2,7,8}$, F Marullo ${ }^{1,2,8}$, F Chiacchiera ${ }^{3,7}$, A Musaró ${ }^{4}$, JYJ Wang ${ }^{5}$, L Latella ${ }^{1,6}$ and PL Puri, ${ }^{\star 1,2}$
}

Previous works have established a unique function of MyoD in the control of muscle gene expression during DNA damage response in myoblasts. Phosphorylation by DNA damage-activated ABL tyrosine kinase transiently inhibits MyoD-dependent activation of transcription in response to genotoxic stress. We show here that ABL-MyoD signaling is also an essential component of the DNA repair machinery in myoblasts exposed to genotoxic stress. DNA damage promoted the recruitment of MyoD to phosphorylated Nbs1 (pNbs1)-containing repair foci, and this effect was abrogated by either $A B L$ knockdown or the $A B L$ kinase inhibitor imatinib. Upon DNA damage, MyoD and pNbs1 were detected on the chromatin to MyoD target genes without activating transcription. DNA damage-mediated tyrosine phosphorylation was required for MyoD recruitment to target genes, as the $A B L$ phosphorylation-resistant MyoD mutant (MyoD Y30F) failed to bind the chromatin following DNA damage, while retaining the ability to activate transcription in response to differentiation signals. Moreover, MyoD Y30F exhibited an impaired ability to promote repair in a heterologous system, as compared with MyoD wild type (WT). Consistently, MyoD-null satellite cells (SCs) displayed impaired DNA repair that was rescued by reintroduction of MyoD WT but not by MyoD Y30F. In addition, inhibition of ABL kinase prevented MyoD WT-mediated rescue of DNA repair in MyoD-null SCs. These results identify an unprecedented contribution of MyOD to DNA repair and suggest that ABL-MyOD signaling coordinates DNA repair and transcription in myoblasts.

Cell Death and Differentiation (2013) 20, 1664-1674; doi:10.1038/cdd.2013.118; published online 20 September 2013

MyoD is a transcriptional activator of skeletal myogenesis during embryonic and postnatal life. ${ }^{1-3}$ Although MyoD is competent to activate transcription of target genes in differentiating muscle cells, ${ }^{4}$ its expression in proliferating, undifferentiated myoblasts, before their differentiation suggests that MyoD function can be extended beyond its ability to activate transcription.

The advent of genome-wide technology has permitted the identification of previously unanticipated MyoD targets, including genes implicated in the regulation of cell cycle, apoptosis and DNA repair.,6 Moreover, the pervasive genome distribution of MyoD identified by chromatin immunoprecipitation (ChIP)-sequence studies ${ }^{7}$ suggests a genomewide function of MyoD in the regulation of events distinct from the direct activation of muscle genes and consistent with a potential control of genome surveillance in myoblasts.

MyoD levels in proliferating muscle cell lines are cell cycle regulated, with peaks of expression detected in $\mathrm{G} 1$ and $\mathrm{S}$ phases. $^{8}$ This expression pattern differs from that of Myf $5^{8}$ and is reminiscent of the expression pattern observed during adult myogenesis, when MyoD expression is not detected in quiescent SCs, but is induced in SCs activated by regeneration cues. ${ }^{9}$ An active role of MyoD during $S$ phase is suggested by the impaired proliferation potential of MyoDnull $S C s^{10,11}$ and by the recently identified $S$ phase-specific function of MyoD in activating the transcription of genes implicated in DNA synthesis. ${ }^{12}$ Collectively, these findings indicate a specific role for MyoD in activated SCs undergoing rounds of DNA replication after leaving quiescence. ${ }^{13}$

Quiescent SCs are typically protected from genotoxic insults by their anatomical position (the satellite cell (SC) niche beneath the basal lamina of myofibers), which insulates them from environmental cues, ${ }^{14}$ and by being confined to the G0/G1 phase of the cell cycle. Upon exposure to regeneration cues, SCs become exposed to multiple sources of genotoxic stress. For instance, muscle injury perturbs the myofiber architecture leading to disruption of SC niche and consequent exposure to potential genotoxins released by the regenerative environment. Moreover, activated SCs undergo multiple rounds of replication; hence, they are exposed to the

\footnotetext{
${ }^{1}$ Epigenetics and Regenerative Medicine, IRCCS Fondazione Santa Lucia, Rome, Italy; ${ }^{2}$ Muscle Development and Regeneration, Sanford-Burnham Institute for Medical Research, La Jolla, CA, USA; ${ }^{3}$ Laboratory of Signal Dependent Transcription, Department of Translational Pharmacology (DTP), Consorzio Mario Negri Sud, Santa Maria Imbaro 66030, Italy; ${ }^{4}$ Institute Pasteur Cenci-Bolognetti, DAHFMO-Unit of Histology and Medical Embryology, IIM, Sapienza University of Rome, Rome, Italy; ${ }^{5}$ Division of Hematology-Oncology, Department of Medicine, Moores UCSD Cancer Center, 3855 Health Sciences Drive, La Jolla, CA, USA and ${ }^{6}$ Institute of Translational Pharmacology, National Research Council of Italy, Via Fosso del Cavaliere 100, Rome, Italy

${ }^{*}$ Corresponding author: PL Puri, Muscle Development and Regeneration, Sanford-Burnham Medical Research Institute, 10901 North Torrey Pines Road, La Jolla, 92037, USA. Tel: 858 6463161; E-mail: pl.puri@ hsantalucia.it or Ipuri@sanfordburnham.org

${ }^{7}$ Current Address: Department of Experimental Oncology, European Institute of Oncology (IEO), Via Adamello 16, I-20139 Milan, Italy

${ }^{8}$ These authors contributed equally to this work.

Keywords: MyoD; ABL; DNA damage; chromatin; DNA repair

Abbreviations: DDR, DNA damage response; SCs, Satellite cells; GM, growth medium; DM, differentiation medium; MMS, methyl methane sulfonate; DOX, doxorubicin; MyHC, myosin heavy chain; MCK, muscle creatine kinase; Edu, 5-ethynyl-2'-deoxyuridine; PLA, proximity ligation assay

Received 31.10.12; revised 22.5.13; accepted 21.6.13; Edited by G Melino; published online 20.9.13
} 
replicative stress - the 'S-phase intrinsic' DNA damage arising from stalled replication forks. ${ }^{15}$ Previous work has shown that MyoD is regulated by DNA damage signaling via $A B L-$ mediated tyrosine phosphorylation that inhibits the transcriptional potential of MyoD - a key event in the differentiation checkpoint triggered by genotoxic stress. ${ }^{16}$ Recent work revealed that DNA damage-activated differentiation checkpoint is functional during developmental myogenesis and identified a unique ability to respond to DNA damage signaling that discriminates MyoD from Myf5. ${ }^{17}$

The differentiation checkpoint coordinates DNA repair and muscle gene expression during cell cycle; ${ }^{18}$ however, it is unknown how the repair and transcription machineries are alternatively and coordinately used in myoblasts exposed to genotoxic stress. ${ }^{19}$ Here, we show that $A B L-M y o D$ signaling is an essential component of the DNA repair machinery in activated SCs exposed to the genotoxic cues. Tyrosine phosphorylation by DNA damage-activated ABL directs MyoD recruitment to DNA repair foci at target genes and is required for MyoD-dependent DNA repair. MyoD-deficient SCs exhibit an impaired DNA repair activity that can be restored by reintroduction of MyoD wild type (WT) but not by a DNA damage-phosphorylation-resistant mutant. On the basis of these data, we propose that DNA damage-activated ABL signaling to MyoD coordinates the temporal execution of DNA repair and activation of muscle gene transcription.

\section{Results}

Following DNA damage, the recruitment of multiprotein complexes into foci at DNA lesions is the essential step to initiate DNA repair. The key initiators of DNA damage response (DDR) are the PI3K-like kinases ATM, ATR and DNA-PK, which propagate the DNA damage signaling by phosphorylating several downstream targets, including $\mathrm{H}_{2} \mathrm{AX}^{20}$ and Nbs1 - a component of the DNA repair MRE11-RAD50-NBS1 complex. ${ }^{21}$ Nuclear staining for phosphorylated $\mathrm{H} 2 \mathrm{AX}(\gamma \mathrm{H} 2 \mathrm{AX})$ and $\mathrm{pNbs} 1$ readily appears after DNA damage with typical distribution in discrete foci, which mark the sites of active DNA repair. Indeed, C2C12 myoblasts exposed to distinct DNA-damaging agents showed punctate nuclear staining for $\gamma \mathrm{H} 2 \mathrm{AX}$ and pNbs1 that reflected the activation of DDR (Supplementary Figure 1).

Upon DNA damage, the spatial redistribution of DNA damage-responsive proteins leads to the transient assembly of the repair machinery at the DNA lesions via indirect interactions. Proximity ligation assay (PLA) is the optimal technology to visualize colocalization of proteins that are in close proximity, often reflecting their simultaneous recruitment to specific sites rather than direct interactions, as it detects the fluorescence signal generated by two antibodies when bound to proteins close within least $30 \mathrm{~nm}^{22,23}$ (see also Materials and Methods). We used PLA to monitor the potential redistribution of MyoD and pNbs1 into nuclear foci. ${ }^{21}$ PLA detected the colocalization of MyoD and pNbs 1 in the nuclei of C2C12 myoblasts that were exposed to different sources of DNA damage (Figures $1 a$ and $b$ ), suggesting the coexistence of these proteins in large multiprotein complexes. DNA damage-activated $A B L$ signaling to $M y o D$ has been previously shown in $\mathrm{C} 2 \mathrm{C} 12$ myoblasts, ${ }^{16}$ and recent work established the biological role of MyoD phosphorylation by DNA damage-activated $A B L$ in regulating skeletal myogenesis during mouse development. ${ }^{17}$ We used shRNA technology to determine the role of $A B L$ in DNA damage-dependent recruitment of MyoD at DNA damage foci in $\mathrm{C} 2 \mathrm{C} 12$ myoblasts. $A B L$ knockdown effectively reduced $A B L$ protein levels (Figure 1c) and completely abolished the formation of MyoD/pNbs1 foci in C2C12 myoblasts exposed to DNA damage (Figures 1a and b). Moreover, pharmacological inhibition of the $\mathrm{ABL}$ kinase activity with imatinib demonstrated the requirement of $A B L-$ mediated phosphorylation for the colocalization of MyoD and pNbs1 following DNA damage (Figures 1d and e). Importantly, inhibition of $A B L$ kinase did not affect the formation of $\mathrm{pNbs} 1$ foci, indicating the specificity of the inhibition of MyoD-pNbs1 colocalization (Figure 1f).

The data described above indicated an unprecedented recruitment of MyoD to DNA repair complex, in response to DNA damage-activated $A B L$, suggesting the possibility that $A B L$ signaling to MyoD could be involved in DNA repair. We therefore investigated whether ABL-MyoD signaling could participate to the DNA repair in myoblasts exposed to DNA damaging agents. We used alkaline comet assay to evaluate the efficiency of DNA repair, and the relative contribution of $\mathrm{ABL}$ kinase in $\mathrm{C} 2 \mathrm{C} 12$ myoblasts exposed to DNA damaging agents with or without pre-incubation with the $\mathrm{ABL}$ kinase inhibitor imatinib. The kinetics of tail moment reduction detected by the comet assay reflects the resolution of the DNA lesions generated by doxorubicin (DOX), as it correlated with the disappearance of $\gamma \mathrm{H} 2 \mathrm{AX}$ foci (Supplementary Figure 2). After exposure to DOX, DNA damage was readily detectable in $\mathrm{C} 2 \mathrm{C} 12$ myoblasts, with the ensuing DNA repair that was observed in control myoblasts but was dramatically impaired upon inhibition of $\mathrm{ABL}$ kinase (Figure $1 \mathrm{~g}$ and Supplementary Figure 2). To directly assess the role of

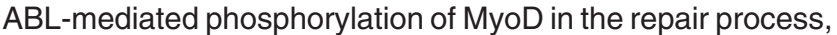
we compared the ability of MyoD WT versus the phosphorylation-resistant Y30F mutant in DNA repair efficiency upon exposure to DOX (Figure 2a). To avoid the presence of endogenous MyoD, we ectopically expressed either MyoD WT or Y30F mutant in mouse fibroblasts and then exposed them to DOX. Direct comparison of the repair kinetics in these two conditions showed that MyoD Y30F-expressing fibroblasts displayed an impaired ability to repair the DNA damage, as compared with MyoD WT (Figure 2a). Consistently, $\gamma \mathrm{H} 2 \mathrm{AX}$ signal persisted in cells expressing MyoD Y30F mutant $48 \mathrm{~h}$ after the DNA damage but were not detected in cells expressing MyoD WT at the same time point (Figure 2b). This evidence reveals the importance of $A B L$-mediated phosphorylation of MyoD in the DNA repair process.

MyoD is a transcription factor with a pervasive, genomewide chromatin distribution through interaction with E-box sequences. ${ }^{7}$ We used ChIP to detect chromatin recruitment of MyoD upon exposure to DNA damage and the potential association with DNA repair proteins. We initially monitored the global chromatin recruitment of MyoD and pNbs 1 by nanodrop quantification of immuno-purified DNA. To determine the role of $A B L-m e d i a t e d$ phosphorylation of MyoD, we ectopically expressed either myc-tagged MyoD WT or the ABL phosphorylation-resistant MyoD Y30F mutant in 10T1/2 fibroblasts and performed a comparative ChIP analysis. 
a
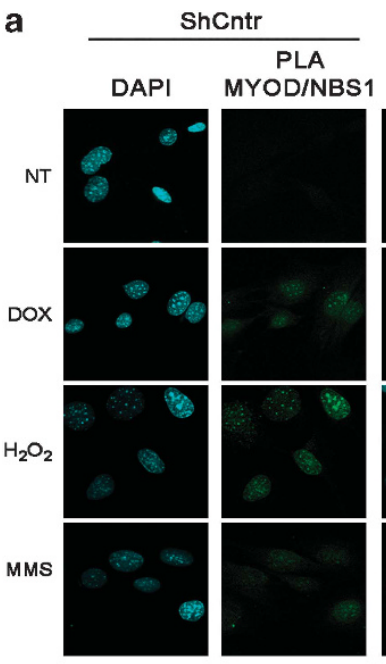

d
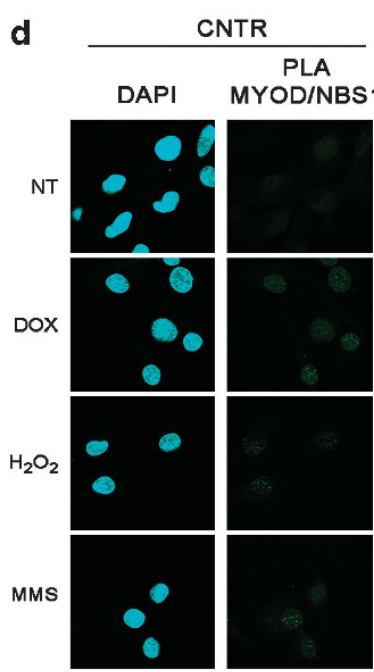

MYOD/NBS
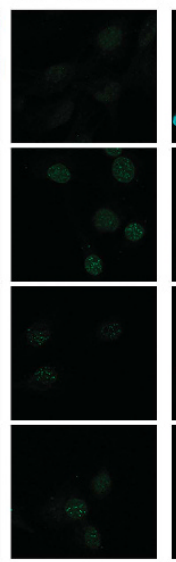

f

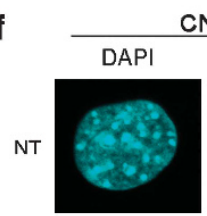

CNTR
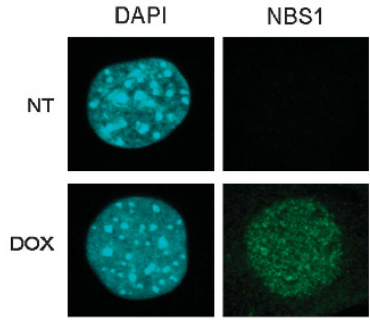
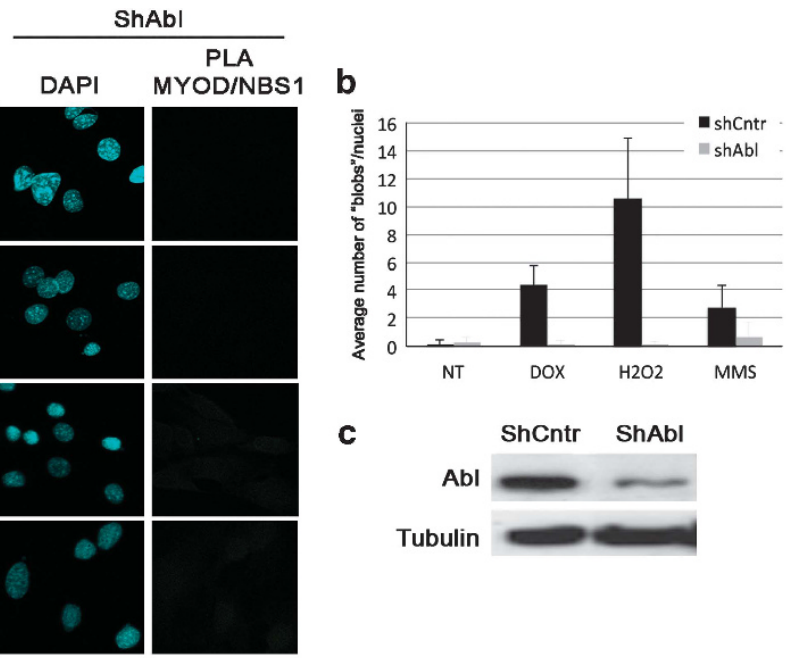

c
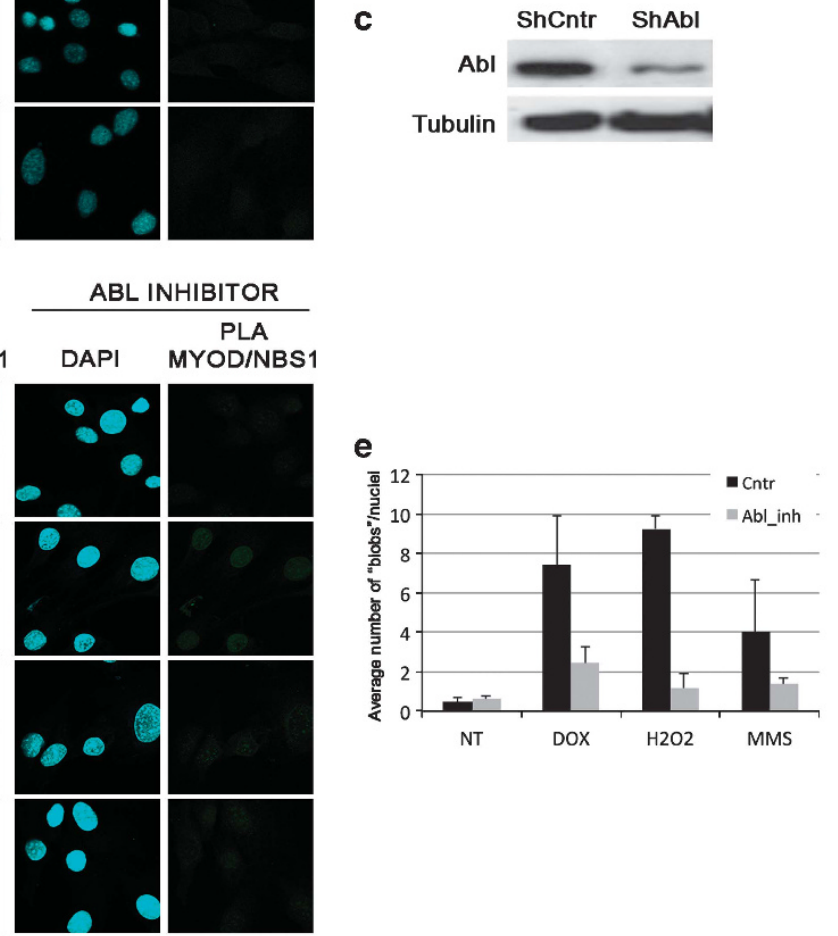

Figure 1 (a and d) PLA was used to monitor nuclear 'in situ' interactions between MyoD and pNbs1 in the nuclei of C2C12 myoblasts exposed to genotoxic stress. (a) $\mathrm{C} 2 \mathrm{C} 12$ cells were infected with retrovirus carrying shCntr or a shAbl sequence. Thirty-six hours after infections, cells were plated and treated with the indicated genotoxic drugs, and were then stained for PLA assay. (b) Graph shows the quantification of colocalization, represented as average number of blobs per nuclei (see Materials and Methods for details). (c) Western blot analysis of ABL expression in C2C12 cells infected with shCntr or shAbl. Tubulin was used as a loading control. (d) C2C12 cells were pretreated with Abl inhibitor imatinib (ABL INHIBITOR) or vehicle alone (CNTR), and then exposed to the indicated genotoxic treatments and stained for PLA assay. (e) Graph shows the quantification of colocalization, represented as average number of blobs per nuclei (see Materials and Methods for details). (f) Immunofluorescence analysis on C2C12 cells pretreated with Abl inhibitor imatinib (ABL INHIBITOR) or vehicle alone (CNTR), and then treated or not with DOX $3 \mu$ M. One hour after treatment, cells were fixed with 4\% PFA and immunostained for pNbs1. DAPI was used to mark nuclei. (g) Alkaline comet assay performed in $\mathrm{C} 2 \mathrm{C} 12$ cells pretreated with imatinib (ABLi) or vehicle alone (Ctrl) and then treated or not with DOX $3 \mu \mathrm{M}$. One hour after treatment, cells were washed and collected at different times, as indicated in the graph. Tail moment values at each time point are represented in the graphs

pNbs1-chromatin interactions were reproducibly detected by ChIP in fibroblasts exposed to DNA damage regardless the presence of MyoD WT or mutant (Figure 3a, right panel), consistent with a recruitment on DNA damage sites randomly distributed throughout the genome. Interestingly, DNA damage increased the chromatin binding of myc-MyoD WT but not myc-MyoD Y30F (Figure 3a, left panel). As the ability of MyoD to activate transcription is inhibited by DDR signaling 
via $A B L-m e d i a t e d$ phosphorylation, ${ }^{16}$ we asked whether MyoD/pNbs1 interactions could be detected on the chromatin of MyoD target genes. Re-ChIP experiments revealed the DNA damage-induced enrichment of myc-MyoD WT and pNbs1 on the chromatin of MyoD target genes, such as myogenin promoter and muscle creatine kinase (MCK) enhancer (Figure 3b). By contrast, myc-MyoD Y30F/pNbs1 interactions were not detected on the chromatin of the same genes in fibroblasts exposed to DNA damage (Figure 3b), despite similar (or even higher) expression levels of MyoD Y30F and MyoD WT (Figure 3c). These results demonstrate that MyoD and pNbs1 are recruited to DNA damage repair foci on the chromatin of MyoD target genes, and ABL-mediated phosphorylation of tyrosine 30 is required for DNA damageinduced MyoD/pNbs1-chromatin interaction.

We next determined whether endogenous MyoD could be recruited to the chromatin of target genes in myoblasts exposed to different types of genotoxic agents (Figure 3d). In parallel, we evaluated the transcriptional output of DNA damage-induced chromatin recruitment of MyoD on target genes by monitoring their expression by real-time quantitative PCR (q-PCR; Figure 3e). ChIP analysis revealed a DNA damage-induced association of $M y o D$ to the regulatory elements of target genes, such as myogenin promoter and MCK enhancer, in myoblasts exposed to distinct genotoxic agents (DOX, methyl methane sulfonate (MMS), and hydrogen peroxide $\left(\mathrm{H}_{2} \mathrm{O}_{2}\right.$; Figure $3 \mathrm{~d}$, left panel). It is noteworthy that the magnitude of the chromatin enrichment was comparable to that detected after exposure to differentiation cues (differentiation medium (DM) conditions). No significant chromatin enrichment was observed on the $\mathrm{IgH}$ enhancer, which contains an E-box that is not bound by MyoD (Figure 3d, left panel). E-box-driven transcription of muscle genes by MyoD is typically accompanied by specific events, such as chromatin recruitment of coactivators and histone modifications permissive for transcription. ${ }^{1,24-26}$ In myoblasts, MyoD-mediated recruitment of acetyltransferases ${ }^{27}$ to the chromatin generates localized hyperacetylation that was detected throughout the genome of myoblasts. ${ }^{7}$ Interestingly, DNA damageinduced binding of MyoD on the chromatin of myogenin promoter and MCK enhancer correlated with histone hyperacetylation in undifferentiated myoblasts, albeit with a reduced extent as compared with differentiating myocytes (DM conditions; Figure 3d, right panel). However, the DNA damage-induced chromatin binding of MyoD and hyperacetylation did not activate transcription of target genes (Figure 3e). By contrast, recruitment of MyoD to the same sequences and hyperacetylation (Figure $3 d$ ) activated gene transcription under differentiation-induced (DM) conditions (Figure 3e). We therefore investigated the effect on chromatin of MyoD recruitment in response to DNA damage by monitoring additional histone modifications that reflect a chromatin conformation either repressive (H3K27 trimethylation; H3K27me3) or permissive (H3K4 trimethylation; H3K4me3) for transcription. In parallel, we monitored the engagement of serine 5 phosphorylated polymerase II (Polll-ser5) at the same genes. Supplementary Figure 3 shows that, at variance with DM-induced MyoD chromatin binding to target genes that correlated with local enrichment in $\mathrm{H} 3 \mathrm{~K} 4 \mathrm{~m} 3$ and Polll-ser5 engagement, DNA damage-induced MyoD binding to the same genes produced an opposite pattern, with increased H3K27me3, decreased H3K4me3 and absence of Polll-ser5 engagement, as compared with DM conditions. This evidence reveals two distinct modalities of MyoD recruitment to the chromatin of target genes, with opposite effects on transcription. MyoD recruitment to myogenin promoter and MCK enhancer upon DNA damage was also detected in fibroblasts ectopically expressing myc-MyoD WT (Figure 3f). Instead, myc-MyoD Y30F was unable to bind myogenin promoter and MCK enhancer under the same experimental conditions, although its ability to bind these target genes under DM conditions was unaltered (Figure 3f). Thus, DNA damage signaling directs the chromatin recruitment of MyoD to target genes, via tyrosine phosphorylation, without activating gene transcription.

$A B L$ is expressed both in myoblasts and myotubes but is predominantly nuclear in proliferating myoblasts, whereas it relocalizes in the cytoplasm of differentiated myotubes. ${ }^{16}$ In proliferating cells, ABL kinase activity is cell cycle regulated being the $S$ phase permissive for activation of nuclear $A B L .{ }^{28,29}$ Thus, we turned our interest on the ABL signaling to MyoD during the 'S-phase intrinsic' DDR. To investigate the relationship between MyoD, S-phase and activation of DNA damage signaling, we monitored the temporal expression of MyoD, 5-ethynyl-2'-deoxyuridine (EdU) incorporation and $\gamma \mathrm{H} 2 \mathrm{AX}$ staining in $\mathrm{C} 2 \mathrm{C} 12$ myoblasts rendered quiescent by serum starvation and induced to re-enter the cell cycle by serum stimulation. This protocol significantly enriches for myoblasts transitioning through the S-phase between 24 and $36 \mathrm{~h}$ after serum stimulation. Quiescent myoblasts do not express MyoD (Figures $4 \mathrm{a}$ and d), as previously reported, ${ }^{8}$ and were negative for EdU incorporation (Figures $4 a$ and $c$ ) and $\gamma \mathrm{H} 2 \mathrm{AX}$ staining (Figures $4 \mathrm{a}$ and b). However, a progressive enrichment of MyoD-expressing cells that incorporated EdU (Figures 4a and c) and displayed $\gamma \mathrm{H} 2 \mathrm{AX}$ staining (Figures $4 a$ and $b$ ) was observed upon serum stimulation, indicating the relationship between MyoD expression and S-phase intrinsic DNA damage.

Upon injury, the simultaneous disruption of the SC niche and the exposure to regeneration cues activate SCs to undergo rounds of replication, thereby exposing them to various sources of genotoxic cues, including S-phase intrinsic DNA damage and oxidative stress. We therefore investigated the relationship between MyoD expression and the DNA damage signaling in injury-activated SCs undergoing replication. We monitored the expression of MyoD together with that of the SC marker Pax7 and the DNA damage signaling target $\gamma \mathrm{H} 2 \mathrm{AX}$ in the nuclei of SCs. In unperturbed muscles, quiescent SCs are typically marked as Pax7positive/MyoD-negative cells and do not display $\gamma \mathrm{H} 2 \mathrm{AX}$ nuclear foci (Supplementary Figure 4). In regenerating muscles, at 3 days post injury, we observed an increased number of Pax7-positive cells, some of which expressed MyoD and showed $\gamma \mathrm{H} 2 \mathrm{AX}$ nuclear staining (Supplementary Figure 4). Notably, all MyoD-expressing cells were positive for $\gamma \mathrm{H} 2 \mathrm{AX}$ nuclear staining (Supplementary Figure 4), indicating a tight correlation between MyoD expression and the appearance of $\gamma \mathrm{H} 2 \mathrm{AX}$ foci in injury-activated SCs. These data suggest that during muscle regeneration a DNA damage signaling is activated in MyoD-expressing SCs undergoing proliferation. 


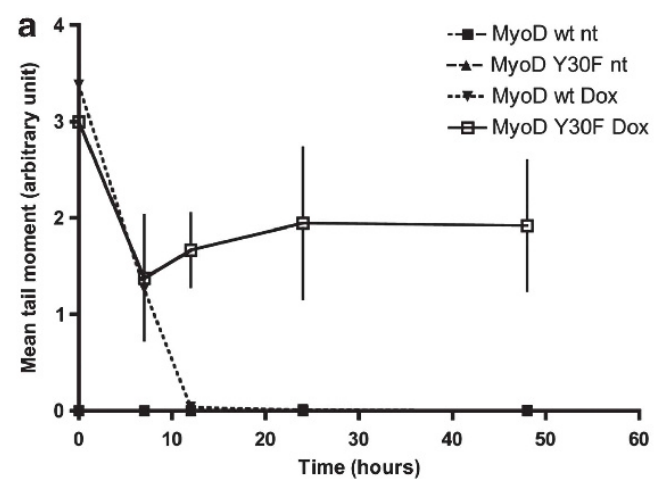

b
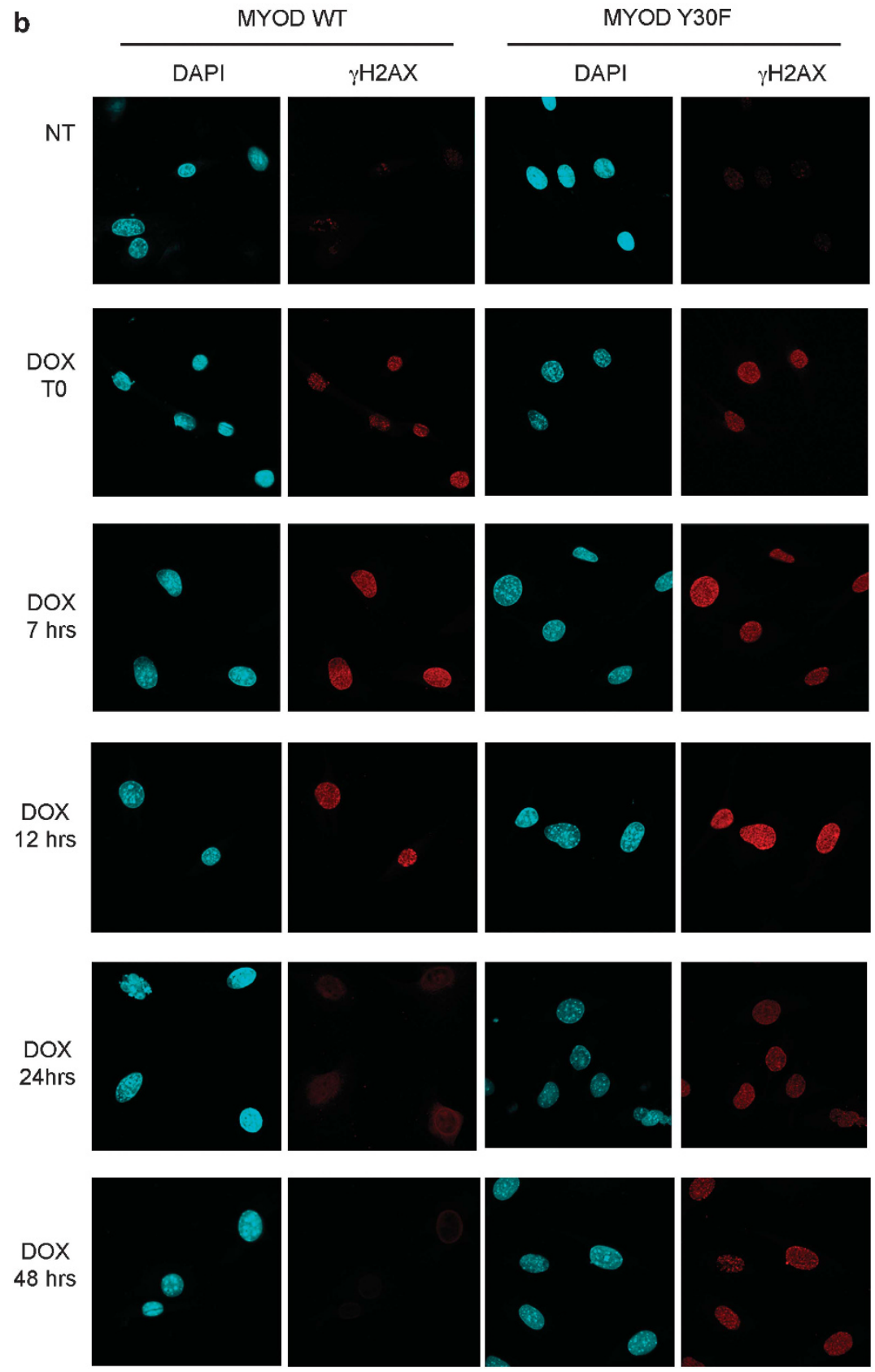
Although the key role of $\mathrm{ABL}$ in the differentiation checkpoint in $\mathrm{C} 2 \mathrm{C} 12$ myoblasts and during development has been documented, ${ }^{16,17}$ whether $A B L-M y o D$ signaling mediates a DNA damage-activated differentiation checkpoint during postnatal myogenesis (that is, muscle regeneration) has not been established. To address this question, we isolated SCs from single myofibers of $\mathrm{ABL}^{\mathrm{fl} / \mathrm{fl}}$ mice and assessed their ability to differentiate into myosin heavy chain (MyHC)-positive myotubes upon exposure to DNA damage, after ablation of $\mathrm{ABL}$ by infection with adenovirus-expressing $\mathrm{CRE}$ recombinase. The myogenic potential of $A B L^{\mathrm{fl} / \mathrm{fl}} \mathrm{SCs}$ was intact, regardless the presence of $A B L$ (Supplementary Figure 5; compare GFP-CNTR with GFP-CRE-expressing cells). However, although DNA damage inhibited the formation of MyHC-positive myotubes from ABL-expressing SCs (GFP-CNTR), CRE-mediated deletion of $A B L$ gene rendered SCs insensitive to DNA damage-dependent inhibition of myotube formation (adeno-GFP-CRE; Supplementary a
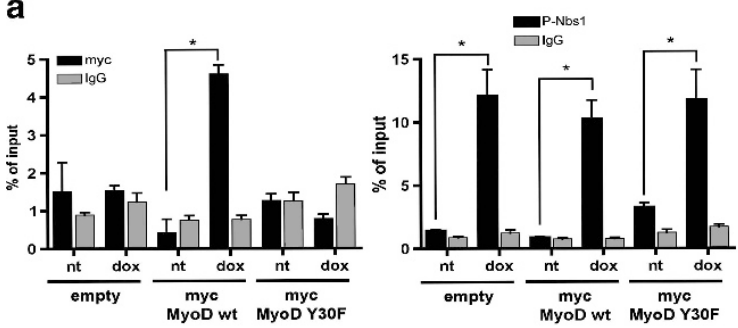

d
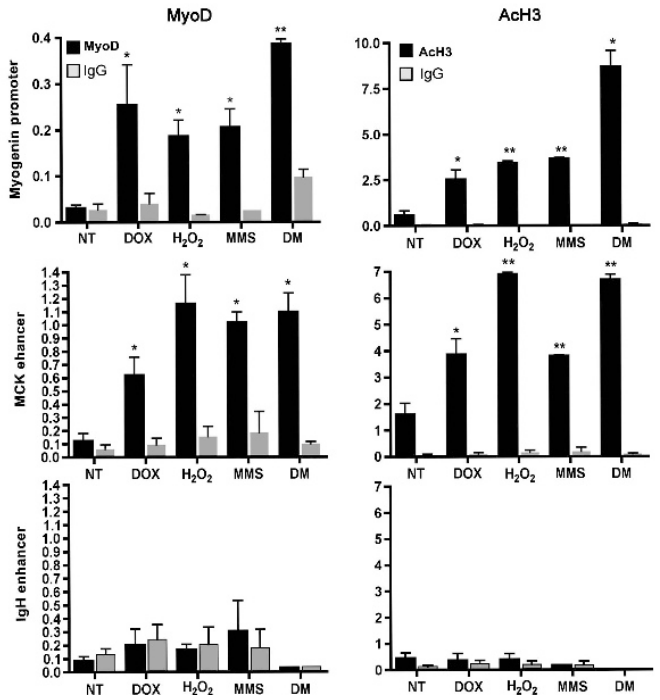
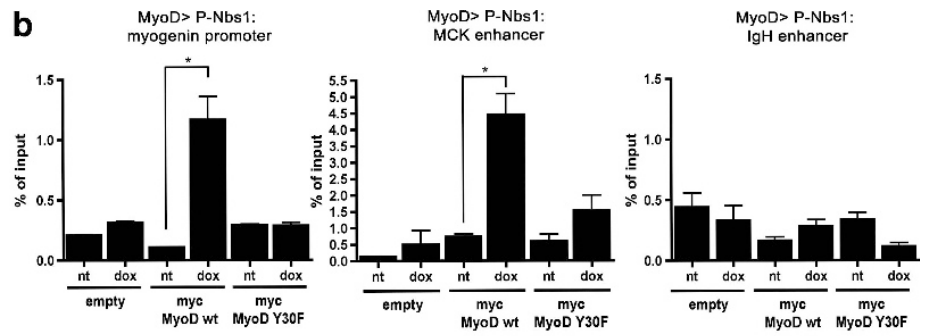

C
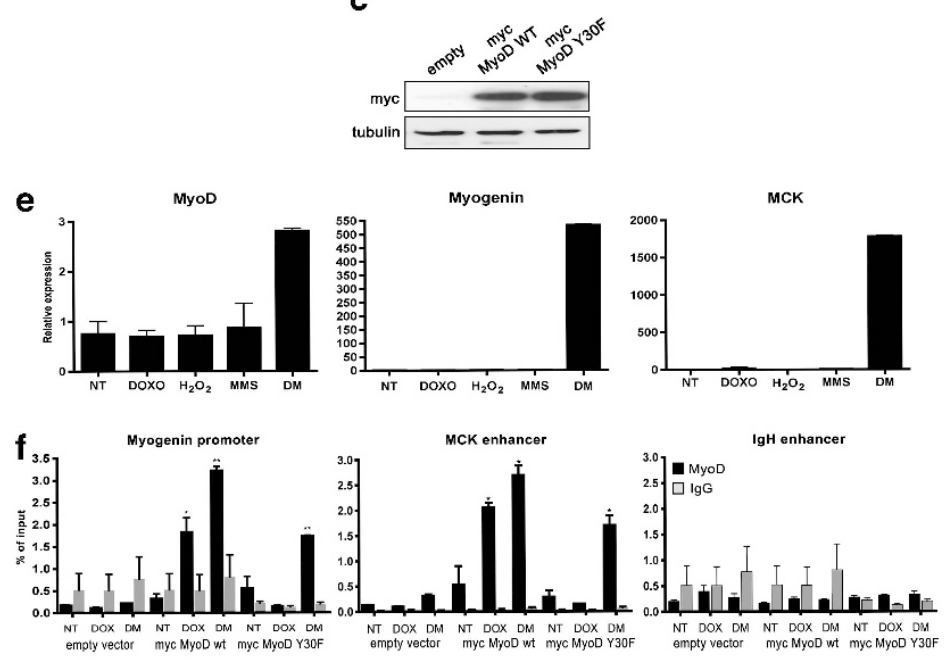

Figure 3 Chromatin interactions of MyoD and pNbs 1 in myoblasts following DNA damage. ChIP and re-ChIP were performed in C3H/10T1/2 fibroblasts transfected with pcDNA3-myc (empty), pcDNA3-myc-MyoD WT (myc MyoD WT) or pcDNA3-myc-MyoD Y30F (myc MyoD Y30F). Thirty-six hours after transfection, cells were untreated (nt) or treated with DOX $(0.4 \mu \mathrm{M})$ for $15 \mathrm{~h}$ and then collected. (a) ChIP on nuclear extracts was performed with antibodies against myc (left panel) and pNbs1 (right panel) as compared with control IgG. Graphs show DNA quantification by nanodrop of immuno-purified DNA, as normalized against the input DNA after single ChIP. Before decrosslinking, a fraction of each sample was eluted and used for the Re-ChIP (shown in b). (b) Samples eluted from myc ChIP were then incubated with anti-pNbs1 antibody (MyoD > PNbs1, $\mathbf{b}$ left). In addition, samples eluted from PNbs1 ChIP were incubated with anti-myc antibody (PNbs1 > MyoD, $\mathbf{b}$ right). q-PCR amplification of DNA isolated from re-ChIP MyoD $>$ PNbs1. Primers were used to amplify myogenin promoter, MCK enhancer region and IgH enhancer control region, as normalized against the input DNA. Values are mean \pm S.E.M. $P$-values showing statistical significance by the Student's $t$-test between the DOX and the NT sample are indicated $\left({ }^{*} P<0.05\right)$. (c) Western blot on nuclear lysates showing the levels of transfected plasmids and the loading control. (d) ChIP with the indicated antibodies were performed to detect the chromatin binding of MyoD (left panel) and $\mathrm{H} 3$ hyperacetylation (right panel) on myogenin promoter, MCK enhancer and immunoglobulin $\mathrm{H}$ (IgH) enhancer in $\mathrm{C} 2 \mathrm{C} 12$ myoblasts treated with the indicated genotoxins for $15 \mathrm{~h}$, while incubated in proliferation (GM). After treatment, cells were collected and processed for ChIP, or shifted in DM for $24 \mathrm{~h}$ and then collected. $\mathrm{ChIP}$ on nuclear extracts was performed with antibodies against MyoD, $\mathrm{AcH} 3$ and control IgG. Graph shows q-PCR values normalized against the input DNA. Values are mean \pm S.E.M. $P$-values showing statistical significance by the Student's $t$-test between each treated and the untreated (NT) sample are indicated ( $\left.{ }^{\star} P<0.05,{ }^{* \star} P<0,005\right)$. (e) q-PCR analysis of MyoD, Myogenin and MCK transcripts of RNA isolated from C2C12 myoblasts cultured in the conditions are indicated above. Values are mean \pm S.E.M. (f) ChIP analysis of the myogenin promoter and MCK enhancer was performed in C3H/10T1/2 fibroblasts transfected with pcDNA3-myc (empty vector), pcDNA3-myc-MyoD WT (myc MyoD WT) or pcDNA3-myc-MyoD Y30F (myc MyoD Y30F). Cells were treated with DOX $(0.4 \mu \mathrm{M})$ for $15 \mathrm{~h}$ and then collected, or shifted in DM for $24 \mathrm{~h}$ and then collected. ChIP on nuclear extracts was performed with antibodies against myc and control lgG. Graph shows q-PCR values normalized against the input DNA. Values are mean \pm S.E.M. $P$-values showing statistical significance by the Student's $t$-test between each treated and the untreated (NT) sample are indicated $\left({ }^{\star} P<0.05,{ }^{* \star} P<0.005\right)$

Figure 2 C3H/10T1/2 fibroblasts were transfected with pcDNA3-myc-MyoD WT (MyoD WT) or pcDNA3-myc-MyoD Y30F (MyoD Y30F) and treated with DOX $3 \mu$ M or not (nt). (a) Alkaline comet assay was performed. One hour after treatment, cells were washed and collected at different times, as indicated in the graph. Tail moment values at each time point are represented in the graphs. (b) Immunofluorescence analysis was performed. One hour after treatment, cells were washed and fixed with $4 \%$ PFA at different times, as indicated in the panel and then immunostained with $\gamma \mathrm{H} 2 \mathrm{AX}$. DAPI was used to mark nuclei 
a
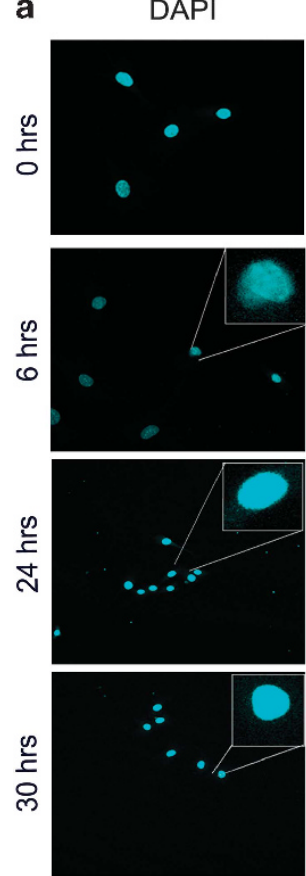

MyoD
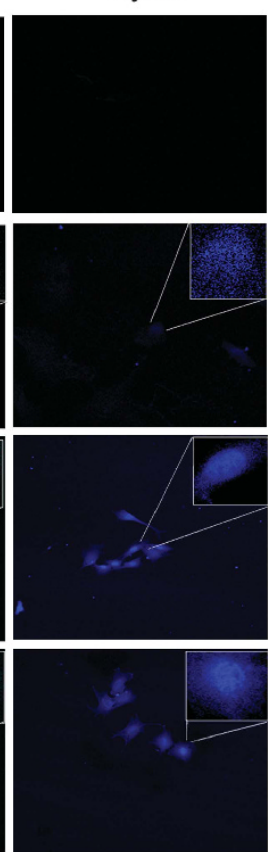

EdU
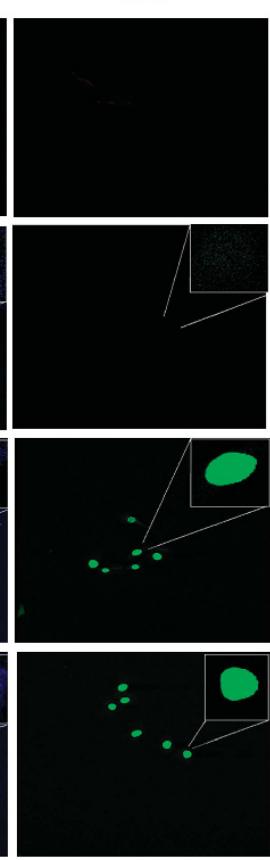
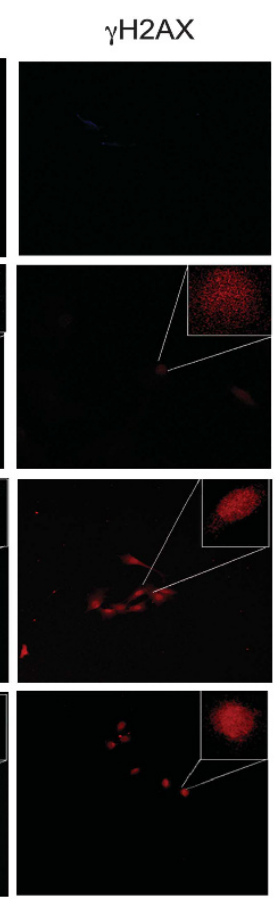
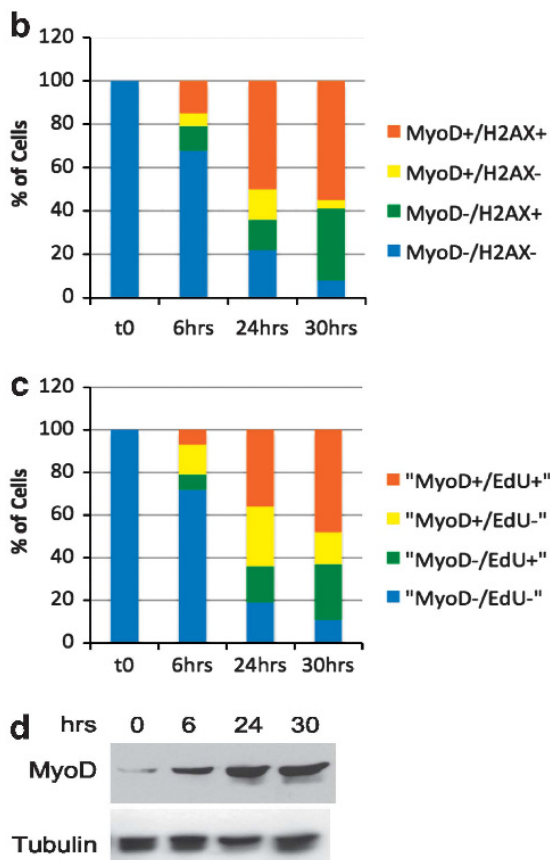

Figure 4 S-phase coincides with nuclear detection of $\mathrm{MyoD}$ and $\gamma \mathrm{H} 2 \mathrm{AX}$ in $\mathrm{C} 2 \mathrm{C} 12$ myoblasts. (a) Immunofluorescence staining on synchronized $\mathrm{C} 2 \mathrm{C} 12 \mathrm{2ellls}$. $\mathrm{C} 2 \mathrm{C} 12$ $\left(2 \times 10^{4}\right)$ were plated in $60 \mathrm{~mm}$ dishes and shifted into $0.1 \% \mathrm{FBS}$ for $48 \mathrm{~h}$ in order to achieve cellular quiescence. Stimulation with $20 \% \mathrm{FBS}$ medium was performed to synchronously restart the cell cycle. Cells were harvested at time points 6,24 and $30 \mathrm{~h}$ post serum stimulation. Two hours before cellular fixation, cells were exposed to $10 \mathrm{uM}$ EdU pulse. Cells were immunostained with $\gamma \mathrm{H} 2 \mathrm{AX}$ and MyoD. Nuclei were counterstained with DAPI. DNA synthesis was revealed by using the EdU Kit from Invitrogen.

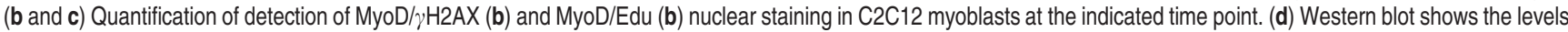
of MyoD at each time point. Tubulin was used as loading control

Figure 5). This result confirms at the genetic level the essential role of $\mathrm{ABL}$ in mediating the DNA damage-activated differentiation checkpoint in satellite muscle cells.

We next evaluated the involvement of $A B L-m e d i a t e d$ phosphorylation of MyoD in DNA repair of SCs by performing alkaline comet assay in SCs isolated by FACS from wild-type or MyoD-null mice, and by determining the effect of reintroduction of MyoD WT or Y30F. SCs from wild-type mice showed a gradual and age-dependent increase in comet tail moment, which is a readout of unrepaired DNA lesions and reflects a progressive impairment in the DNA repair efficiency (Figure 5a) that is typically observed in adult stem cells of aging organisms. ${ }^{30,31}$ Strikingly, MyoD-null SCs showed a consistently increased comet tail moment as compared with their wild-type counterpart, at all the ages analyzed, with the highest difference (almost fourfold increase) detected in 12-month-old mice (Figure 5a). This finding indicates a deficiency in DNA repair ability of adult muscle stem cells lacking MyoD. As MyoD is expressed in SCs undergoing activation in response to developmental and regeneration cues, the increased DNA damage observed in MyoD-null SCs can be attributed to those cells that have participated to skeletal myogenesis during development and muscle turnover in adult life. We tested whether reintroduction of MyoD could restore DNA repair ability in MyoD-null SCs. SCs isolated from MyoDnull mice were exposed to DOX and their DNA repair ability was monitored at different time points for $48 \mathrm{~h}$ post DNA damage. DOX-treated MyoD-null SCs (mock DOX) showed a DNA damage signal that was not detected in undamaged (non-treated) MyoD-null SCs (mock nt; Figure 5b). A significant delay of DNA repair response was observed in DOX-treated MyoD-null SCs, resulting in the incomplete repair of DNA $48 \mathrm{~h}$ after damage (Figure $5 \mathrm{~b}$ ). Reintroduction of MyoD WT completely restored the DNA damage repair ability of MyoD-null SCs, with complete disappearance of detectable DNA lesions after $12 \mathrm{~h}$ from the exposure to DOX (Figure 5b). Consistently, reintroduction of the ABL-resistant MyoD Y30F mutant did not restore the DNA repair ability of MyoD-null SCs (Figure 5b). In addition, ABL inhibitor prevented MyoD WT-mediated repair in MyoD-null SCs (Figure $5 c$ ), thereby confirming the essential role of $A B L$ signaling to enable the repair activity of MyoD. These data indicate that MyoD is an essential mediator of the DNA repair machinery in muscle SCs and that this function is dependent on phosphorylation by DNA damage-activated $A B L$ tyrosine kinase. The impaired DNA repair ability detected in MyoD-null SCs shown in Figures $5 a$ and $b$ suggests that unrepaired DNA lesions could accumulate over time in SCs within MyoD-null muscles in vivo, leading to a persistent DNA damage signaling that can be revealed by $\gamma \mathrm{H} 2 \mathrm{AX}$ staining. Muscle of 2-month-old wild-type mice did not show any Pax7-expressing SCs that was also positive for $\gamma \mathrm{H} 2 \mathrm{AX}$ staining, whereas sporadic, but reproducibly detectable, double-positive Pax $7 / \gamma \mathrm{H} 2 \mathrm{AX}$ cells were observed in age-paired MyoD-null mice (Figures $5 \mathrm{~d}$ and e). A low amount of Pax $7 / \gamma \mathrm{H} 2 \mathrm{AX}$ double-positive cells could be detected in 12-month-old wild-type mice; however, muscles of 12-month-old MyoD-null mice showed much 

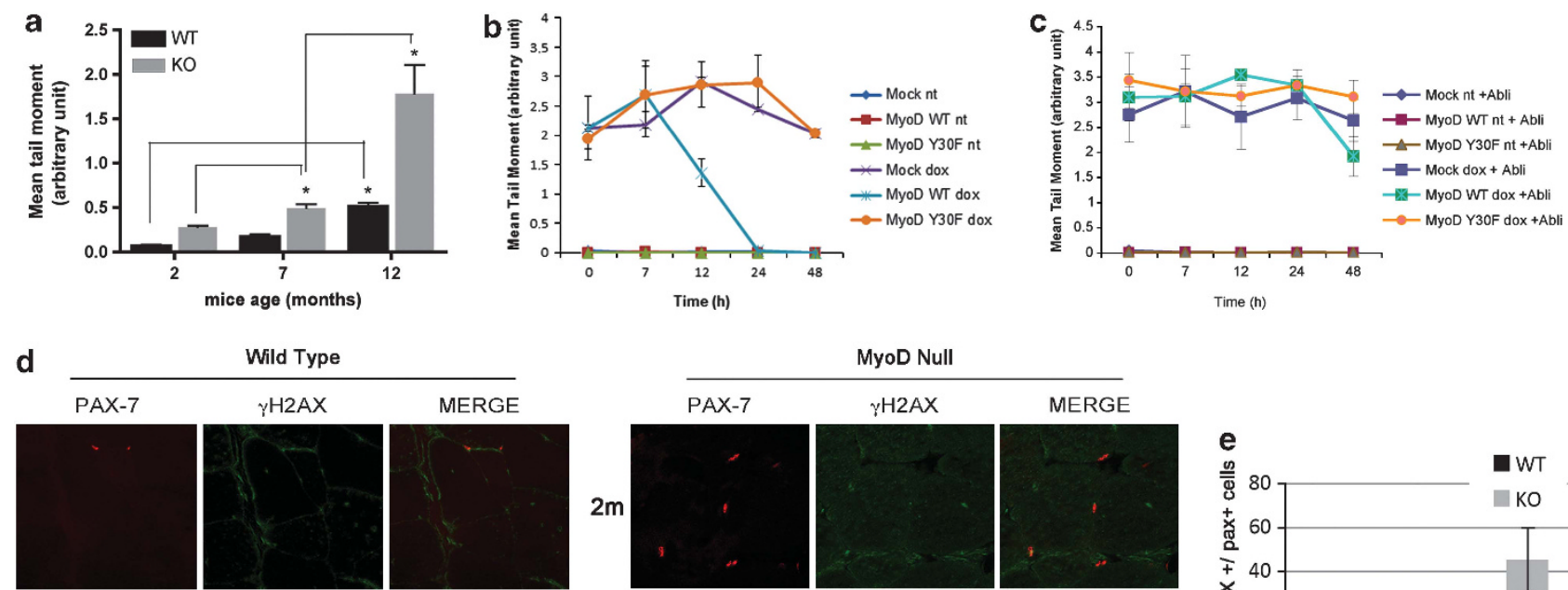

Wild Type
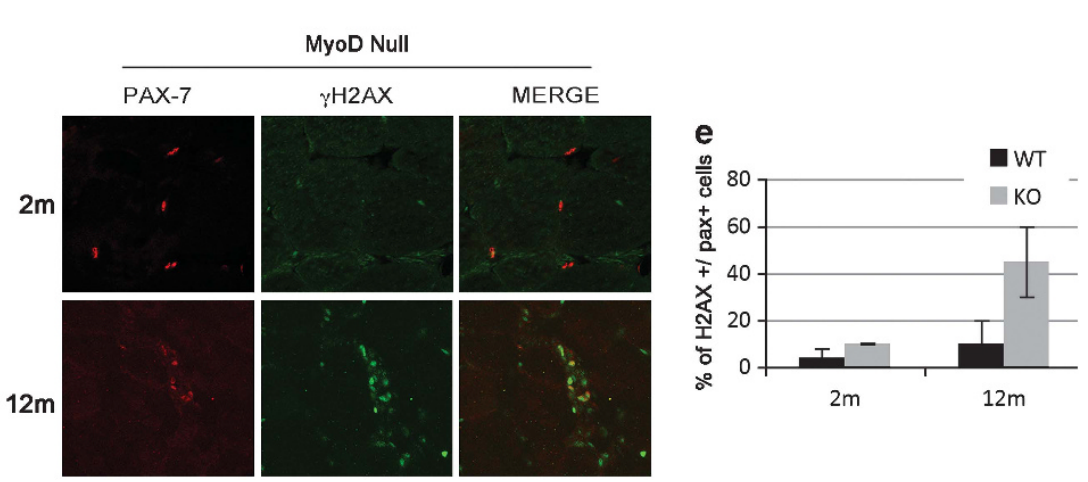

Figure 5 MyoD-null SC show DNA repair impairment that is rescued by MyoD WT, but not by MyoD Y30F mutant. (a) Alkaline comet assay in SCs isolated from WT and MyoD-null (KO) mice of 2, 7, and 12 months of age. SCs were isolated using FACS sorting and immediately used for comet assay. (b and $\mathbf{c}$ ) Comet assay in SCs isolated from MyoD-null mice, transfected with pcDNA3-myc (mock), pcDNA3-myc-MyoD WT (MyoD WT) or pcDNA3-myc-MyoD Y30F (MyoD Y30F) and treated with DOX 1,5 $\mu$ M or not (nt) (b), or pretreated with imatinib (ABLi) or vehicle alone (Cntr) and then treated or not with DOX $(1.5 \mu \mathrm{M})$ (c). After $1 \mathrm{~h}$, cells were washed and collected at different time points, as indicated in the graph. Tail moment values at each time point are represented in the graphs. (d) Immunofluorescence staining for Pax7 (red) and $\gamma$-H2AX (green) of quadriceps transverse sections of 2-month-aged (2 m) and 12-month-aged (12 m) wild-type and MyoD-null mice. (e) Graph shows the number of $\gamma-\mathrm{H}_{2} \mathrm{AX}^{+}$within the pax7 ${ }^{+}$ cells. At least 10 cells in three different sections, in three independent experiments were counted

higher number of Pax7-expressing SCs positive for $\gamma \mathrm{H} 2 \mathrm{AX}$ staining (Figures $5 \mathrm{~d}$ and $\mathrm{e}$ ).

\section{Discussion}

The DDR of tissue progenitors, such as SCs, is relatively unexplored. This is surprising when considering the challenge posed to adult stem cells by the highly genotoxic environment within regenerating tissues. For instance, in response to muscle injury, previously quiescent SCs undergo several cycles of replication while being exposed to growth factors, differentiation and genotoxic cues released within the regenerating muscles. Simultaneous exposure to such a variety of signals might trigger different and potentially conflicting programs, such as proliferation, DNA repair and terminal differentiation. Thus, coordinated execution of these events might be crucial for the maintenance of the genomic stability of regenerating myofibers and to ensure their longterm performance. Our identification of MyoD as central effector of the DDR in SCs suggests an unprecedented mechanism by which the DNA damage signaling to a cell typespecific transcription factor might coordinate DNA repair and the differentiation program.

MyoD expression in SCs coincides with their activation and exposure to regeneration cues, including the S-phaseassociated DNA damage arising from the frequent stalling of the replication forks. The intra-S-phase DNA damage signaling leads to the activation of several downstream effectors, including the tyrosine kinase $A B L .{ }^{29}$ We have previously demonstrated that DNA damage-activated $A B L$ phosphorylates MyoD on tyrosine 30 , leading to a reversible inhibition of its transcriptional ability. ${ }^{16}$ We now show that ABL-mediated phosphorylation also promotes a previously unrecognized ability of MyoD to participate in DNA repair in myoblasts exposed to genotoxic insults. This finding suggests that phosphorylation of tyrosine 30 promotes a switch of function and transiently converts MyoD from being a transcriptional activator to an effector of the DNA repair. We propose that this switch might temporally prioritize the execution of the DNA repair toward the activation of the myogenic program by MyoD, according to the concept of DNA damage-activated differentiation checkpoint. ${ }^{32}$

Although the precise mechanism that enables MyoD to contribute to DNA repair will be the object of future studies, our data suggest that DNA damage-dependent phosphorylation of the N-terminal of MyoD promotes its recruitment to the chromatin of target genes together with DNA repair factors, while inhibiting its transcriptional ability. This evidence suggests a model of DNA repair by transcriptional activators that is substantially different from the transcription-coupled repair but is rather consistent with a previously proposed ability of transcription factors to contribute to DNA repair. ${ }^{33}$ Interestingly, an increase in histone acetylation at MyoDbound sequences was detected in response to DNA damage, possibly to favor the access of the repair machinery to the DNA lesions. ${ }^{34}$ Although this might suggest a promiscuous use of components of transcriptional machinery to promote DNA repair, our data clearly indicate that DNA repair and transcriptional activities of MyoD rely on distinct mechanisms. Dissociation of these two activities is well provided by a MyoD 
mutant impaired in DNA repair activity (MyoD Y30F), which retains full transcriptional competence. ${ }^{16}$ This is consistent with the notion that MyoD tyrosine phosphorylation by DNA damage-activated $\mathrm{ABL}$ inhibits the interaction with the transcriptional machinery and stimulates the DNA repair activity.

What is the biological impact of DNA damage regulation of MyoD activity? Our previous studies reported on an evolutionarily acquired genotoxic response that discriminates MyoD from Myf5 and differentially regulates hypaxial versus epaxial myogenesis. ${ }^{17}$ This response during developmental myogenesis is likely finalized to ensure the correct formation and the genomic integrity of the adult musculature, and can be extended to the adult muscle progenitors - the SCs - once challenged by genotoxic threats. In both conditions, holding the differentiation program of muscle progenitors until the completion of the DNA repair prevents the formation of differentiated muscles with unresolved DNA lesions. This is of particular importance when considering that terminally differentiated myotubes have an impaired DNA repair machinery. ${ }^{35}$ Thus, the correct execution of the DNA damage-activated differentiation in muscle progenitors safeguards the genome integrity of differentiated myofibers.

An impaired ability of MyoD to respond to the DNA damage might lead to an aberrant activation of muscle gene expression before the completion of DNA repair, leading to the accumulation of unrepaired lesions and to the progressive loss of the genomic integrity of the myofibers. Moreover, defective DNA damage signaling to MyoD might impair the DNA repair ability of the satellite returning quiescence, and therefore progressively affect the genomic integrity of the reserve pool of muscle stem cells. Overall, the progressive accumulation of genomic instability can impair the performance of differentiated myofibers and the regeneration potential of SCs, two typical features observed in aged muscles. Because of the intimate relationship between DNA damage, genetic instability, cellular senescence and age-dependent decline of muscle performance, the DNA damage-activated differentiation checkpoint might be an essential regulator of muscle aging.

Another possible outcome of deregulated DDR in SCs is a constitutive activation of DNA damage signaling, which might arise in conditions of aberrant regeneration, such as the repeated cycles of regeneration of dystrophic muscles that expose SCs to an increased frequency of S-phase events and to a genotoxic environment. Recent studies have reported on the genetic instability of muscles from different models of muscular dystrophies, ${ }^{36}$ suggesting that the high 'regenerative pressure' of dystrophic muscles might overcome the ability of MyoD to safeguard the genome integrity. For instance, the constitutive activation of IGF1 signaling in dystrophic muscles can overcome the DNA damageactivated differentiation checkpoint in $\mathrm{SCs}^{18}$ and force the accretion of 'corrupted' genetic material to regenerating myofibers, thereby compromising their function. Future studies should determine whether an altered DNA damage signaling to MyoD contribute to the pathogenesis of muscular dystrophies.
Materials and Methods

Cell culture and treatments. The murine $\mathrm{C} 2 \mathrm{C} 12$ skeletal muscle cells, C3H10T1/2 fibroblasts and 293 ampho-packaging cells were cultured in growth medium (GM; Dulbecco's modified Eagle's medium (DMEM) supplemented with $10 \%$ fetal bovine serum (FBS), $2 \mathrm{mM}$ glutamine). Muscle differentiation was induced by incubating cells in DM (DMEM supplemented with $2 \%$ horse serum (HS)).

Single muscle fibers with associated SCs were isolated as described in Rosenblatt et al. ${ }^{37}$ Briefly, the hind limb muscles were digested with collagenase and single myofibers were plated on matrigel (Sigma (St. Louis, MN, USA) $1 \mathrm{mg} / \mathrm{ml}$ ECM gel)-coated dishes in GM1 (DMEM supplemented with 10\% horse serum (Gibco-Invitrogen, Carlsbad, CA, USA), 0.5\% chick embryo extract (MP Biomedicals, Santa Ana, CA, USA) and penicillin-streptomycin (Gibco) at $37^{\circ} \mathrm{C}$. Three days later, the medium was replaced with proliferation medium (GM2 - 20\% FBS, $10 \%$ HS and $1 \%$ chick embryo extract in DMEM) to promote proliferation of detached cells (delaminated SCs). After 4-5 days, the cells were allowed to differentiate replacing the medium with DM $(2 \% \mathrm{HS}$ and $0.5 \%$ chick embryo extract in DMEM).

Genotoxic treatments were carried out by incubating cells in GM for $12-16 \mathrm{~h}$ to the following DNA-damaging agents: $0.4 \mu \mathrm{M} \mathrm{DOX}, 75 \mu \mathrm{M}$ MMS and $50 \mu \mathrm{M} \mathrm{H}_{2} \mathrm{O}_{2}$. The acute treatments were carried out for $1 \mathrm{~h}$ with the following dosage: $3 \mu \mathrm{M} \mathrm{DOX}$ and $250 \mu \mathrm{M}$ MMS. In SCs the acute treatment was performed with DOX $(1.5 \mu \mathrm{M})$.

Where indicated, cells were pretreated with the pharmacological Abl inhibitor imatinib $5 \mu \mathrm{M}$ for $12 \mathrm{~h}$. SCs were pretreated with the pharmacological Abl inhibitor imatinib $(2.5 \mu \mathrm{M})$ for $12 \mathrm{~h}$.

For synchronization experiment, $2 \times 10^{4} \mathrm{C} 2 \mathrm{C} 12$ were plated in 60 -m dishes and shifted into $0.1 \% \mathrm{FBS}$ for $48 \mathrm{~h}$ in order to achieve cellular quiescence. Stimulation with $20 \%$ FBS medium was performed to synchronously restart the cell cycle. Cells were harvested at time points 6,24 and $30 \mathrm{~h}$ post serum stimulation. Two hours before cellular fixation, cells were exposed to $10 \mathrm{mM}$ EdU pulse.

DNA transfection and infection. Where indicated, cells were transfected with Lipofectamine 2000 (Invitrogen, Carlsbad, CA, USA) according to the manufacturer's instructions. The following plasmids have been used: pcDNA3-myc empty vector, pcDNA3-myc-MyoD WT and pcDNA3-myc-MyoD Y30F. Thirty-six hours after transfection, cells were used for the specific experiments. For retrovirus production, pSuper sh control and pSuper sh $\mathrm{Abl}^{38}$ (kindly provided by D. Barilà) were transfected in 293 ampho-packaging cells. Virus-containing supernatants were collected $48 \mathrm{~h}$ post transfection, and were passed through a $0.45-\mu \mathrm{m}$ filter.

$\mathrm{SCs}$ derived from $\mathrm{ABL}^{\mathrm{fl} / \mathrm{fl}}$ mice ${ }^{17}$ were infected with adeno-GFP-CRE or adenoGFP-control. After 4-5 days, the cells were allowed to differentiate replacing the medium with DM ( $2 \% \mathrm{HS}$ and $0.5 \%$ chick embryo extract in DMEM). GFP expression marked successfully infected cells, whereas disappearance of $\beta$ gal staining indicated successful CRE-LOX recombination and gene deletion in infected SCs.

Mice and in vivo procedures. MyoD-null mice (C57/BL10 strain) were kindly provided by Dr. Rudnicki and were compared with their normal counterpart. $\mathrm{ABL}^{\mathrm{flffl}}$ mice have been previously described. ${ }^{17}$ Muscle injury was performed by intramuscular injection of $10^{-5} \mathrm{M}$ cardiotoxin (Sigma). We injected $60 \mu \mathrm{l}$ of $10^{-5} \mathrm{M}$ cardiotoxin into quadriceps, $40 \mu \mathrm{l}$ into gastrocnemius and $20 \mu \mathrm{l}$ into tibialis anterior.

All experimental procedures were approved by the internal Animal Research Ethical Committee according to the Italian Ministry of Health and complied with the $\mathrm{NIH}$ Guide for the Care and Use of Laboratory Animals.

Cell preparation and FACS analysis. For FACS of SCs from wild-type or MyoD-null mice, hind limb muscles were minced and digested in HBSS (Gibco) containing $2 \mu \mathrm{g} / \mathrm{ml}$ collagenase A (Roche, Indianapolis, IN, USA), $2.4 \mathrm{U} / \mathrm{ml}$ dispase I (Roche), $10 \mathrm{ng} / \mathrm{ml}$ DNase I (Roche), $0.4 \mathrm{mM} \mathrm{CaCl} 2$ and $5 \mathrm{mM} \mathrm{MgCl}$ for $90 \mathrm{~min}$ at $37^{\circ} \mathrm{C}$. Cells were stained with primary antibodies (10 ng/ml) CD31-PacificBlue (Invitrogen), CD45-eFluor450 (eBioscience, San Diego, CA, USA), Ter119-eFluor450 (eBioscience), Sca-1-FITC (BD Pharmingen, San Diego, CA, USA), CD34-Biotin (eBioscience) and $\alpha 7$ integrin-APC (kindly provided by Dr. Rossi) for $30 \mathrm{~min}$ on ice. A subsequent incubation, $30 \mathrm{~min}$ on ice, with Streptavidin-PE-Cy7 (1/500; BD Pharmingen) was performed. Cells were finally washed and resuspended in HBSS containing $0.2 \%(w / v)$ $\mathrm{BSA}$ and $1 \%(\mathrm{v} / \mathrm{v})$ penicillin-streptomycin. Flow cytometry analysis and cell sorting were performed on a DAKO-Cytomation MoFlo High Speed Sorter. SCs were isolated as Ter119-/CD45-/CD31-/CD34+/a7-integrin + ISca-1-cells. 
Proximity ligation assay. $\mathrm{C} 2 \mathrm{C} 12$ cells were plated on coverslips and treated as indicated. Cells were fixed with $4 \%$ paraformaldehyde for $10 \mathrm{~min}$ at room temperature (RT) and incubated 10 min with $0.1 \%$ triton in PBS. Rehydration was performed with PBS washes. Blocking was performed using the Duolink blocking solution following the manufacturer's indication (Duolink in situ PLA kit, Olink, Uppsala, Sweden). Cells were then incubated at $37^{\circ} \mathrm{C}$ overnight with ant MyoD (5.8, Dako, Glostrup, Denmark) and PNbs1 (Epitomics, Burlingame, CA, USA) primary antibodies. The incubation with the PLA probes, hybridization, ligation, amplification, detection and mounting was performed following Duolink kit indications (Duolink in situ PLA kit, Olink). Nuclei were counterstained with DAPI.

Images were acquired with Zeiss LSM5 Pascal confocal microscope (Carl Zeiss, Oberkochen, Germany) and analyzed with the Blobfinder software ${ }^{22}$ that was used to localize and quantify the blobs per nuclei. The average of blobs per nuclei in at least 10 cells from three independent experiments \pm S.E.M. is reported in the graphs.

Alkaline comet analysis. C3H10T1/2 mouse fibroblasts, $\mathrm{C} 2 \mathrm{C} 12$ muscle cells and SCs from wild-type and MyoD-null mice were treated with $1.5 \mu \mathrm{M}$ DOX for $1 \mathrm{~h}$, and then the medium was replaced to wash out the treatment and cells were harvested at different time points. Cells were analyzed for DNA breaks and repair kinetics as previously described ${ }^{18}$ with minor modifications. Single cells were analyzed with 'TriTek Cometscore version 1.5' software (Tritek Corporation, Sumerduck, VA, USA). The tail moment was used as the measure of DNA damage. One hundred cells for each experimental point were scored.

Histology and immunofluorescence. For immunofluorescence experiments, tibialis anterior muscles were snap frozen in liquid nitrogen-cooled isopentane and then cut transversally.

Cryosections $(10 \mu \mathrm{m})$ were fixed in 4\% PFA for $20 \mathrm{~min}$ and permeabilized with $100 \%$ methanol for $6 \mathrm{~min}$ at $-20^{\circ} \mathrm{C}$. To avoid unspecific binding, muscle sections were first blocked with a solution containing 4\% BSA in PBS and then with antimouse AffiniPure Fab fragments (Jackson, 1:100). Immunostaining with anti-Pax7 (Developmental Studies Hybridoma Bank, University of lowa, IA, USA) and $\gamma-\mathrm{H} 2 \mathrm{AX}$ (Upstate, Lake Placid, NY, USA) was performed overnight at $4{ }^{\circ} \mathrm{C}$ after antigen retrieval with $100 \mathrm{mM}$ sodium citrate. Cy2-conjugated anti-rabbit (Jackson Laboratory, Bar Harbor, ME, USA ) and biotin-conjugated anti-mouse (Jackson) secondary antibody followed by another incubation with Cy3-conjugated streptavidin (Jackson) were used to reveal $\gamma-\mathrm{H} 2 \mathrm{AX}$ and Pax7 signal. Nuclei were visualized by counterstaining with To-Pro3 (Invitrogen).

Cells for immunofluorescence were plated on coverslips and SCs were plated on matrigel-coated coverslips. Cells were fixed with $4 \%$ PFA for $10 \mathrm{~min}$, permeabilized with $0.5 \%$ Triton/PBS and blocked with $4 \%$ BSA in PBS for $1 \mathrm{~h}$ at RT. The following primary antibodies were used: MyoD (5.8, Dako), $\gamma$-H2AX (Upstate), PNbs1 (Epitomics) and MyHC (MF20). Immunostaining with primary antibodies was performed for $1 \mathrm{~h}$ at RT. Antibody binding was revealed using species-specific secondary antibodies coupled to Alexa Fluor 488 or 543 (Molecular Probes, Eugene, CA, USA).

Where indicated, DNA synthesis was revealed by using the EdU Kit from Invitrogen.

Images were acquired at $\times 40$ or $\times 63$ using Zeiss LSM5 Pascal confocal microscope. Fields reported in the figures are representative of all examined fields. Images were assembled using ImageJ software (NIH, Bethesda, MD, USA) and Photoshop software (Adobe Systems Incorporated, San Jose, CA, USA).

Western blot. Total cell extracts (lysis in $50 \mathrm{mM}$ Tris-Hcl pH 8, $125 \mathrm{mM} \mathrm{NaCl}$ $1 \mathrm{mM} \mathrm{DTT}, 5 \mathrm{mM} \mathrm{MgCl} 2,1 \mathrm{mM}$ EDTA, $10 \%$ glycerol and $0.1 \% \mathrm{NP}-40$ supplemented with PMSF and protease inhibitor cocktail) were resolved in SDS polyacrilamide gels and transferred to nitrocellulose membranes (hybond-XL Amersham). Anti Abl Ab3 (Calbiochem, San Diego, CA, USA, kindly provided by D. Barila), MyoD 5.8 (Dako) and anti tubulin alpha (DM1A, neomarkers) were used as primary antibodies. HRP-conjugated secondary antibodies were revealed with the ECL chemoluminescence kit (GE healthcare, Little Chalfont, UK).

RNA extraction and RT-PCR. Total RNA was extracted using Trizol according to the manufacturer's instructions and $0.5-1.0 \mu \mathrm{g}$ of RNA were retrotranscribed using the reverse transcription kit (Applied Biosystems, Foster City, CA, USA). q-PCR was performed to analyze relative gene expression levels using SYBR Green Master mix (Applied Biosystems) following the manufacturer's indications.
Primers sequences are as follow:

MyoD:

Fwd: 5'-CGCGCTCCAACTGCTCTGATGG-3'

Rev: 5'-CTCGACACAGCCGCACTCTTCC-3'

Myogenin:

Fwd: 5'-GGCTCAAGAAAGTGAATGAGGC-3'

Rev: 5'-CGATGGACGTAAGGGAGTGC-3'

MCK:

Fwd: 5'-AGTCCTACACGGTCTTCAAGG-3'

Rev: 5'-AGGAAGTGGTCATCAATGAGC- $3^{\prime}$

GAPDH universal:

Fwd: 5'-CACCATCTTCCAGGAGCGAG-3'

Rev: 5'-CCTTCTCCATGGTGGTGAAGAC-3'

ChIP and re-ChIP. ChIP assay was performed as previously described. ${ }^{39}$ The following antibodies were used: anti-acetylated histone 3 (Upstate), MyoD (mix of SC-760 and Dako 5.8), anti-myc (Santa Cruz, Santa Cruz, CA, USA, SC-789), anti ser 5 Polymerase II (H14, Covance, Paris, France), anti H3K4me3 (Abcam) and H3K27me3 (Abcam, Cambridge, UK). Normal rabbit IgG was used as negative control. One percent of the lysate used in each immunoprecipitation was kept as input. q-PCR was performed on input samples and immunoprecipitated material with the SYBR Green Master Mix (Applied Biosystems). Relative recruitment is calculated as the amount of amplified DNA normalized to input.

Re-ChIP was performed as described in Forcales et al. ${ }^{40}$ Briefly, in Re-ChIP experiments immunoprecipitated material was eluted with DTT $(10 \mathrm{mM})$, and then was diluted 40 times in IP buffer and incubated with a second antibody and processed as in ChIP protocol. A second aliquot was kept as input before the second ChIP.

Primers sequences are as follow:

Myogenin promoter:

Fwd: 5'-TGGCTATATTTATCTCTGGGTTCATG-3'

Rev: 5'-GCTCCCGCAGCCCCT-3'

MCK enhancer:

Fwd: 5'-AGGGATGAGAGCAGCCACTA-3'

Rev: 5'-CAGCCACATGTCTGGGTTAAT-3'

IgH enhancer:

Fwd: 5'-GCCGATCAGAACCAGAACACCTGC-3'

Rev: 5'-TGGTGGGGCTGGACAGAGTGTTTC-3'

\section{Conflict of Interest}

The authors declare no conflict of interest.

Acknowledgements. PLP is a scientist at Sanford Children' Health Center at Burnham and was partly supported by NIAMS (2R01AR052779-06). This work has benefited from research funding from the European Community's Seventh Framework Programme in the project FP7-Health - 2009 ENDOSTEM 241440 (Activation of vasculature associated stem cells and muscle stem cells for the repair and maintenance of muscle tissue) and FILAS (to PLP) and Seventh Framework Programme-Myoage (Grant No. 223576), Fondazione Roma and Ateneo project (to AM). FM was supported by AFM PhD fellowship. LL was supported by a grant from Italian Foreign Ministry (MAE). We thank Dr. Michael Rudnicki for providing MyoD-null mice, Dr. Rossi for providing $\alpha 7$-integrin antibodies and Dr. Barila for providing Abl inhibitor and shRNA vectors.

\section{Author Contributions}

PLP designed and supervised the experiments of the manuscript. MS executed experiments of co-IF, ChIP and analysis of MyoD and ABL-null SCs. FM performed PLA and comet assays. LL performed PLA, IF during cell cycle in C2C12 myoblasts and IF of SCs during regeneration. JYJW provided ABL-CRE mice. FC and AM contributed to the image and data analysis. PLP conceived the experiments, wrote the manuscript and coordinated the revision of the manuscript. All authors discussed and commented the results of the manuscript.

1. Dilworth FJ, Blais A. Epigenetic regulation of satellite cell activation during muscle regeneration. Stem Cell Res Ther 2011; 2: 18. 
2. Lassar A, Munsterberg A. Wiring diagrams: regulatory circuits and the control of skeletal myogenesis. Curr Opin. Cell Biol 1994; 6: 432-442.

3. Tapscott SJ. The circuitry of a master switch: Myod and the regulation of skeletal muscle gene transcription. Development 2005; 132: 2685-2695.

4. Puri PL, Sartorelli V. Regulation of muscle regulatory factors by DNA-binding, interacting proteins, and post-transcriptional modifications. J Cell Physiol 2000; 185: 155-173.

5. Blais A, Tsikitis M, Acosta-Alvear D, Sharan R, Kluger Y, Dynlacht BD. An initial blueprint for myogenic differentiation. Genes Dev 2005; 19: 553-569.

6. Cao Y, Kumar RM, Penn BH, Berkes CA, Kooperberg C, Boyer LA et al. Global and gene-specific analyses show distinct roles for Myod and Myog at a common set of promoters. EMBO J 2006; 25: 502-511.

7. Cao Y, Yao Z, Sarkar D, Lawrence M, Sanchez GJ, Parker MH et al. Genome-wide MyoD binding in skeletal muscle cells: a potential for broad cellular reprogramming. Dev Cell 2010; 18: 662-674.

8. Kitzmann M, Carnac G, Vandromme M, Primig M, Lamb NJ, Fernandez A. The muscle regulatory factors $M y o D$ and myf-5 undergo distinct cell cycle-specific expression in muscle cells. J Cell Biol 1998; 142: 1447-1459.

9. Zammit PS, Golding JP, Nagata Y, Hudon V, Partridge TA, Beauchamp JR. Muscle SCs adopt divergent fates: a mechanism for self-renewal? J Cell Biol 2004; 166: 347-357.

10. Megeney LA, Kablar B, Garrett K, Anderson JE, Rudnicki MA. MyoD is required for myogenic stem cell function in adult skeletal muscle. Genes Dev 1996; 10: 1173-1183.

11. Montarras D, Lindon C, Pinset $C$, Domeyne $P$. Cultured myf5 null and myoD null muscle precursor cells display distinct growth defects. Biol Cell 2000; 92: 565-572.

12. Zhang K, Sha J, Harter ML. Activation of $\mathrm{Cdc} 6$ by $M y o D$ is associated with the expansion of quiescent myogenic SCs. J Cell Biol 2010; 188: 39-48.

13. Zhang K, Sha J, Harter ML. MyoD, a new function: ensuring "DNA licensing". Cell Cycle 2010; 9: 1871-1872.

14. Pallafacchina G, Francois S, Regnault B, Czarny B, Dive V, Cumano A et al. An adult tissue-specific stem cell in its niche: a gene profiling analysis of in vivo quiescent and activated muscle SCs. Stem Cell Res 2010; 4: 77-91.

15. Bartek J, Lukas C, Lukas J. Checking on DNA damage in S phase. Nat Rev Mol Cell Biol 2004; 5: 792-804.

16. Puri PL, Bhakta K, Wood LD, Costanzo A, Zhu J, Wang JY. A myogenic differentiation checkpoint activated by genotoxic stress. Nat Genet 2002; 32: 585-593.

17. Innocenzi A, Latella $L$, Messina $G$, Simonatto $M$, Marullo $F$, Berghella $L$ et al. An evolutionarily acquired genotoxic response discriminates MyoD from Myf5, and differentially regulates hypaxial and epaxial myogenesis. EMBO $R$ 2011; 12: 164-171.

18. Simonatto M, Giordani L, Marullo F, Minetti GC, Puri PL, Latella L. Coordination of cell cycle, DNA repair and muscle gene expression in myoblasts exposed to genotoxic stress. Cell Cycle 2011; 10: 2355-2363.

19. Simonatto $M$, Latella $L$, Puri PL. DNA damage and cellular differentiation: more questions than responses. J Cell Physiol 2007; 213: 642-648.

20. Xu Y, Price BD. Chromatin dynamics and the repair of DNA double strand breaks. Cell Cycle 2011; 10: 261-267.

21. Jackson SP, Bartek J. The DNA-damage response in human biology and disease. Nature 2009; 461: 1071-1078
22. Allalou A, Wahlby C. BlobFinder, a tool for fluorescence microscopy image cytometry. Comput Methods Programs Biomed 2009; 94: 58-65.

23. Fredriksson S, Gullberg M, Jarvius J, Olsson C, Pietras K, Gustafsdottir SM et al. Protein detection using proximity-dependent DNA ligation assays. Nat Biotechnol 2002; 20 473-477.

24. Asp P, Blum R, Vethantham V, Parisi F, Micsinai M, Cheng J et al. Genome-wide remodeling of the epigenetic landscape during myogenic differentiation. Proc Natl Acad Sci USA 2011; 108: E149-E158.

25. Guasconi V, Puri PL. Chromatin: the interface between extrinsic cues and the epigenetic regulation of muscle regeneration. Trends Cell Biol 2009; 19: 286-294.

26. Sartorelli V, Juan AH. Sculpting chromatin beyond the double helix: epigenetic control of skeletal myogenesis. Curr Topics Dev Biol 2011; 96: 57-83.

27. Puri PL, Sartorelli V, Yang XJ, Hamamori Y, Ogryzko VV, Howard BH et al. Differentia roles of p300 and PCAF acetyltransferases in muscle differentiation. Mol Cell 1997; 1 $35-45$.

28. Liu ZG, Baskaran R, Lea-Chou ET, Wood LD, Chen Y, Karin M et al. Three distinct signalling responses by murine fibroblasts to genotoxic stress. Nature 1996; $\mathbf{3 8 4}$ 273-276.

29. Wang JY, Ki SW. Choosing between growth arrest and apoptosis through the retinoblastoma tumour suppressor protein, Abl and p73. Biochem Soc Trans 2001; 29: 666-673.

30. Garinis GA, van der Horst GT, Vijg J, Hoeijmakers JH. DNA damage and ageing: new-age ideas for an age-old problem. Nat Cell Biol 2008; 10: 1241-1247.

31. Wang C, Jurk D, Maddick M, Nelson G, Martin-Ruiz C, von Zglinicki T. DDR and cellular senescence in tissues of aging mice. Aging Cell 2009; 8: 311-323.

32. Polesskaya A, Rudnicki MA. A MyoD-dependent differentiation checkpoint: ensuring genome integrity. Dev Cell 2002; 3: 757-758.

33. Frit $\mathrm{P}$, Kwon K, Coin F, Auriol J, Dubaele S, Salles B et al. Transcriptional activators stimulate DNA repair. Mol Cell 2002; 10: 1391-1401.

34. Bell O, Tiwari VK, Thoma NH, Schubeler D. Determinants and dynamics of genome accessibility. Nat Rev Genet 2011; 12: 554-564.

35. Narciso L, Fortini $P$, Pajalunga D, Franchitto A, Liu $P$, Degan $P$ et al. Terminally differentiated muscle cells are defective in base excision DNA repair and hypersensitive to oxygen injury. Proc Natl Acad Sci USA 2007; 104: 17010-17015.

36. Schmidt WM, Uddin MH, Dysek S, Moser-Thier K, Pirker C, Hoger $\mathrm{H}$ et al. DNA damage, somatic aneuploidy, and malignant sarcoma susceptibility in muscular dystrophies. PLoS Genet 2011; 7: e1002042.

37. Rosenblatt JD, Parry DJ, Partridge TA. Phenotype of adult mouse muscle myoblasts reflects their fiber type of origin. Differentiation 1996; 60: 39-45

38. Furlan A, Stagni V, Hussain A, Richelme S, Conti F, Prodosmo A et al. Abl interconnects oncogenic Met and p53 core pathways in cancer cells. Cell Death Differ 2011; 18 $1608-1616$.

39. Simone C, Forcales SV, Hill DA, Imbalzano AN, Latella L, Puri PL, p38 pathway targets SWL SNF chromatin-remodeling complex to muscle-specific loci. Nat Genet 2004; 36: 738-743.

40. Forcales SV, Albini S, Giordani L, Malecova B, Cignolo L, Chernov A et al. Signal-dependent incorporation of MyoD-BAF60C into Brg1-based SWI/SNF chromatin-remodelling complex. EMBO J 2012; 31: 301-316. 